\title{
Forecasting Daily Reference Evapotranspiration for Shepparton, Victoria, Australia using Numerical Weather Prediction outputs
}

\author{
$\underline{\text { Kushan Perera }}{ }^{\text {a }}$, Andrew Western ${ }^{\text {a }}$, Bandara Nawarathna ${ }^{\text {b }}$, Biju George ${ }^{\text {a }}$ \\ ${ }^{a}$ Department of Infrastructure Engineering, The University of Melbourne, Australia \\ ${ }^{b}$ Environment and Research Division, The Bureau of Meteorology, Australia \\ Email: kushanr@student.unimelb.edu.au
}

\begin{abstract}
Farmers and irrigation system operators make real-time irrigation decisions based on a range of factors including crop water requirement and short-term weather forecasts of rainfall and air temperature. Forecasts of reference crop evapotranspiration $\left(E T_{O}\right)$ can be calculated from numerical weather prediction (NWP) forecasts and $E T_{O}$ has the advantage of being more directly relevant to crop water requirements than air temperature. This paper aims to discuss the forecasting ability of $E T_{O}$ using outputs from the Bureau of Meteorology's operational NWP forecasts derived from the Australian Community Climate and Earth System Simulator - Global (ACCESS-G). The daily $E T_{O}$ forecasts were evaluated for the Shepparton Irrigation Area in Victoria. Forecast performance for $E T_{O}$ was quantified using the root mean squared error (RMSE), coefficient of determination $\left(\mathrm{r}^{2}\right)$, anomaly correlation coefficient (ACC) and mean square skill score (MSSS). Lead times of daily $E T_{O}$ forecasts up to 9 days were compared against $E T_{O}$ calculated using hourly observations from the Shepparton airport automatic weather station. It was found that forecasting daily $E T_{O}$ was better than using the long-term monthly mean $E T_{O}$ for lead times up to 6 days and beyond that the longterm monthly mean was better. The average MSSS of $E T_{O}$ forecasts varied between $64 \%$ and $4 \%$ for 1 to 6 day lead times, respectively. The most influential forecast weather variable for daily $E T_{O}$ forecasts was mean wind speed, air temperature and incoming solar radiation for 1, 2-3 and 4-9 day lead times respectively. Also, it was found that the forecast performance for incoming solar radiation and mean wind speed was relatively poor compared with the air and dew point temperatures.
\end{abstract}

Keywords: $\quad$ Reference evapotranspiration, forecasting, Numerical Weather Prediction, FAO56. 
Kushan Perera et al., Forecasting Daily Reference Evapotranspiration for Shepparton using Numerical Weather Prediction outputs

\section{INTRODUCTION}

Many, if not most real-time irrigation decisions are about supplying the right amount of water at the right time to crops. Predominantly, these decisions can both save water and increase economic benefits. Farmers and irrigation system operators make these real-time irrigation decisions based on a range of factors including crop water requirement and short-term weather forecasts of rainfall and air temperature. To a great extent, these decisions are based on estimates of the near-future crop evapotranspiration. The crop evapotranspiration can be estimated by multiplying reference evapotranspiration $\left(E T_{O}\right)$ with the crop coefficient $\left(K_{c}\right)$, where $K_{c}$ is expressed as the ratio between crop ET and $E T_{O}$ (Jensen, 1968). $E T_{O}$ can be forecasted directly or indirectly. In the direct methods, current and historical data are used to forecast $E T_{O}$ either by time series methods or by computational/artificial neural networks (CNNs or ANNs). In the indirect method, weather variables needed to calculate $E T_{O}$ are forecast (often by numerical weather prediction (NWP) models) and then applied empirical or analytical models, such as Hargraves (Hargreaves and Samani, 1985), Penman (Penman, 1948), Penman-Monteith(Allen et al., 1998) models, to forecast $E T_{O}$.

The simplest and oldest statistical method of forecasting daily $E T_{O}$ is to calculate the long-term monthly mean based on historical observations. Time series models such as autoregressive integrated moving average - ARIMA and autoregressive-moving average - ARMA have also been used to forecast daily, weekly or monthly $E T_{O}$ (Marino et al., 1993, Mohan and Arumugam, 1995, Raghuwanshi and Wallender, 1999). Moreover, CNNs or ANNs have been used to forecast or estimate monthly $E T_{O}$ based on the historical $E T_{O}$ data (Tahir, 1998, Kumar et al., 2002, Trajkovic et al., 2003). However, at the beginning of the $21^{\text {st }}$ century, the forecast performance of mesoscale NWP models has improved significantly. Duce et al. (1999) forecasted $E T_{O}$ 20-70 hours ahead, for six locations in California, United States for a $20 \mathrm{~km}$ grid resolution NWP forecast derived from a mesocale atmospheric simulation model. Subsequently, publically available weather forecasts in China have been used to forecast daily $E T_{O}$ and this work has found that most $E T_{O}$ forecasts were skilful up to 5 lead days (Cai et al., 2007, Xianghong et al., 2011, Tian and Martinez, 2012). Arca et al. (2003) compared 1 to 3 days lead time $E T_{O}$ forecasting performance from ARIMA and ANN models with $E T_{O}$ from the NWP forecasts derived from the limited area model, BOLAM2000 (Arca et al., 2003). They found that ANN performed better than ARIMA, but $E T_{O}$ forecasts using NWP forecasts provided the best results. These results all suggest that $E T_{O}$ can be reliably forecasted using NWP forecasts and that the uncertainties of these $E T_{O}$ forecasts will decline as the performance of the NWP models increases. This would obviously assist farmers and irrigation system operators to reduce the risk embedded in their real-time operational decisions.

Quantification of $E T_{O}$ forecast performance using outputs from NWP models has been limited to certain geographical areas such the United State, China and Chile (Silva et al., 2010, Cai et al., 2007, Arca et al., 2003) and forecast performance varies between models, lead times, locations and climates. Therefore, this paper aims to quantify the forecasting performance for daily $E T_{O}$ using the Bureau of Meteorology's operational NWP forecasts derived from the Australian Community Climate and Earth System Simulator Global model (ACCESS-G). Forecast $E T_{O}$ for lead times of 1 to 9 days for the Shepparton irrigation area in Victoria, Australia is compared against daily $E T_{O}$ calculated using the observed weather variables recorded at the Shepparton airport automatic weather station (AWS). Further, we quantified the forecasting performance for $E T_{O}$ related weather variables, (daily maximum and minimum of air and dew point temperatures, mean daily wind speed and daily incoming solar radiation) and investigated the sensitivity of $E T_{O}$ forecasts to each weather variable to determine which weather variable contributed most to the $E T_{O}$ forecast errors.

\section{MATERIALS AND METHODS}

The study area is Shepparton, Victoria, Australia, which is often referred as the "Food Bowl of Australia" given it produces approximately 25 per cent of Victoria's agricultural production value. Agriculture is dominated by irrigated dairy, pome and stone fruit production, with other agricultural activities related to sheep for wool, beef and dairy cattle. The AWS is located at the Shepparton airport (Figure 1(a)). The latitude, longitude and the elevation are $-36^{\circ} 25^{\prime} 44,145^{\circ} 23^{\prime} 41^{\prime \prime}$ and 113.9 meters above Australian height datum (AHD), respectively. The climate is temperate with a hot summer ( $T_{\text {hot }} \geq 22$ ) but without a dry season (Köppen climate type Cfa) (Peel et al., 2007). The hourly weather variables namely air temperature; relative humidity and wind speed were collected for the period 05 July 1996 to 01 August 2012 to estimate observed daily $E T_{O}$. In the absence of measured daily incoming solar radiation or ground heat flux data, satellite imagery based daily incoming solar radiation data was collected from the Bureau of Meteorology, Australia.

The weather variables needed to forecast daily $E T_{O}$ were collected from the Bureau of Meteorology's operational NWP forecasts, generated using the Australian Community Climate and Earth System Simulator - Global (ACCESS-G). The ACCESS systems are non-hydrostatic, hybrid vertical level structure, 
mesoscale, assimilation and forecast systems developed and tested by the Centre for Australian Weather and Climate Research (CAWCR) (Bureau of Meteorology, 2010). The ACCESS systems were implemented operationally by the operational development subsection of national weather \& oceanographic centre on 17 August 2010 and the spatial resolution of the each NWP ACCESS system is shown in Figure 1(b).
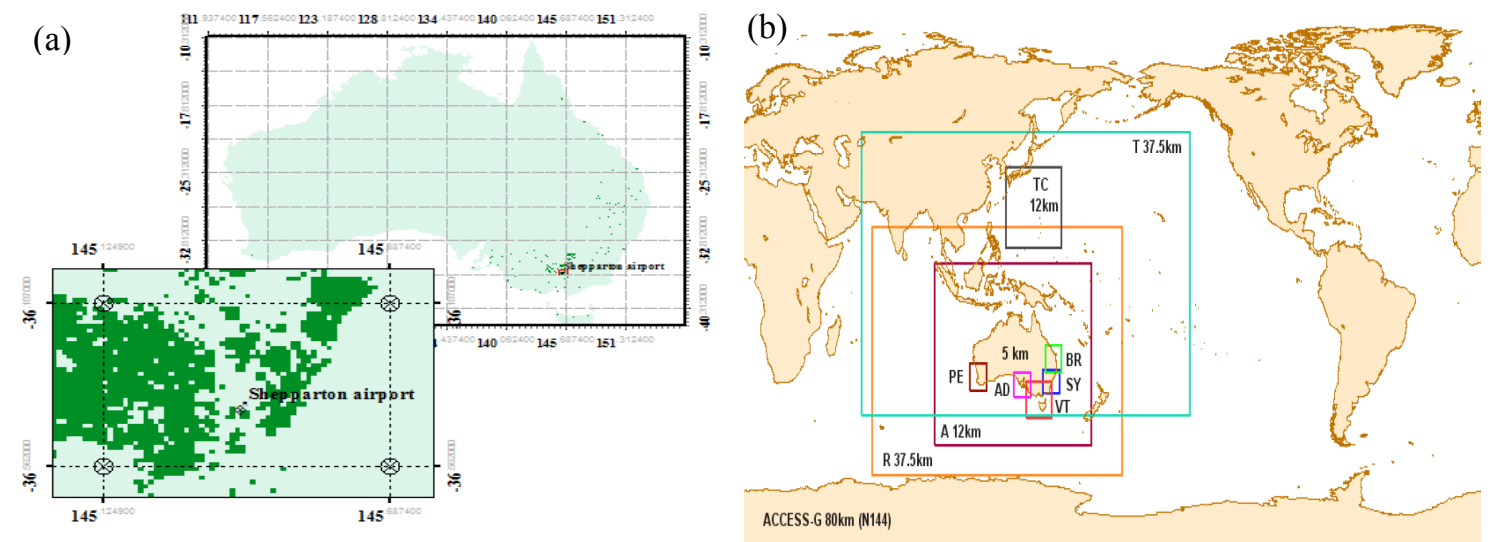

Figure 1. (a) Location of the Shepparton AWS and irrigation agricultural areas as per 2005/06 Australian land use map and (b) Spatial Resolution of ACCESS Models (Bureau of Meteorology 2010))

ACCESS-G assimilates and forecasts twice a day at 0000 and 1200 UTC (i.e. 10.00 AM and 10.00 PM local time) and NWP forecasts are available at 03.50 PM and next day 3.50 AM respectively(Bureau of Meteorology, 2010). We selected NWP forecasts generated for 10.00 AM local time run by considering the local time of NWP forecasts availability. For the study period (17 Aug. 2010 - 01 Aug. 2012), we extracted three hourly NWP forecasts of incoming solar radiation, air temperature, dew point temperature and wind speed corresponding to the four grid points (Figure 1(a)) surrounding the station and linearly interpolated to the AWS location. We note that small-scale spatial variation is likely to be relatively low in this flat landscape.

All daily $E T_{O}$ calculations were made using the FAO56 Penman-Monteith (FAO56-PM) daily $E T_{O}$ equations (Allen et al., 1998). This method has been recommended as the standard method of computing daily $E T_{O}$ (Allen et al., 1998) and numerous studies have demonstrated the superior performances of the FAO56-PM equations compared with other $E T_{O}$ equations (Allen et al., 1989; Chiew et al., 1995; Chen 2005).Net radiation is the difference between the incoming net shortwave radiation and the outgoing net longwave radiation (Allen et al., 1998). Incoming net shortwave radiation was calculated using the collected incoming shortwave solar radiation and albedo of 0.23 . Outgoing net longwave radiation was estimated from the daily maximum and minimum air temperature and relative shortwave radiation, calculated using the collected incoming shortwave solar radiation and calculated clear-sky radiation (Allen et al., 1998).

The performance of daily $E T_{O}$ forecasts were quantified using the root mean squared error (RMSE), correlation coefficient $\left(^{2}\right)$, anomaly correlation coefficient (ACC) (Miyakoda et al., 1972) and mean square skill score (MSSS) (Murphy, 1988). These statistical indices were used to evaluate the performance of $E T_{O}$ forecasts with 1 to 9 days lead times against the daily $E T_{O}$ calculated using observed weather data. These statistical indices are as follows.

(a) The root mean squared error, RMSE is:

(b) The Anomaly Correlation Coefficient (ACC) is:

(c) The Mean Square Skill Score (MSSS) is:

$$
\begin{aligned}
& \text { RMSE }=\left(\sum\left(\mathrm{P}_{\mathrm{i}}-\mathrm{O}_{\mathrm{i}}\right)^{2} / \mathrm{n}\right)^{1 / 2} \\
& \text { ACC }=\frac{\sum\left(P_{i}-\bar{C}\right)\left(O_{i}-\bar{C}\right)}{\left(\sum\left(\mathrm{P}_{\mathrm{i}}-\overline{\mathrm{C}}\right)^{2} \sum\left(\mathrm{O}_{\mathrm{i}}-\overline{\mathrm{C}}\right)^{2}\right)^{1 / 2}} \\
& \text { MSSS }=1-\frac{\sum\left(\mathrm{P}_{\mathrm{i}}-\mathrm{O}_{\mathrm{i}}\right)^{2}}{(n /(n-1))^{2} \sum\left(\mathrm{O}_{\mathrm{i}}-\overline{\mathrm{C}}\right)^{2}}
\end{aligned}
$$

In equations 1-3, $P_{i}$ and $O_{i}$ are the $i^{\text {th }}$ predicted and observed values respectively, $\mathrm{n}$ is the number of observations and $\overline{\mathrm{C}}$ is the climatological or long-term mean monthly observation.

\section{RESULTS AND DISCUSSION}

The long-term observed mean monthly $E T_{O}$ and corresponding box plots of daily $E T_{O}$ for the Shepparton irrigation area are shown in Figure 2 . In each box plot represents the lower $\left(25^{\text {th }}\right)$, middle $\left(50^{\text {th }}\right)$ and upper ( $\left.75^{\text {th }}\right)$ percentile and the bottom and top whiskers represents $5^{\text {th }}$ and $95^{\text {th }}$ percentiles respectively. Long-term monthly mean $E T_{O}$ varies from $1.12 \mathrm{~mm} \mathrm{day}^{-1}$ during mid-winter (July) to $7.30 \mathrm{~mm}$ day $^{-1}$ during mid-summer (January). This strong seasonality results from the variability in solar radiation and air temperature due to the latitude of the Shepparton area. The highest absolute variability in daily $E T_{O}$ occurs during the summer, 
followed by spring and autumn and the lowest is during winter. These inter- and intra-monthly variations in $E T_{O}$ result from the input weather variables (air temperature, dew point temperature, wind speed and incoming solar radiation). Therefore, first we report the forecast performance for these weather variables. Then we report the performance of 1 to 9 day lead time daily $E T_{O}$ forecasts. Finally, the sensitivity of each the $E T_{O}$ forecasts to errors in each weather variable is assessed by substituting one observed weather variable at a time in the $E T_{O}$ forecast, thereby eliminating the forecast error for that variable. While ACCESS-G provides a 240 hour lead time, the lead time of this report was limited to 9 lead days by excluding the $1^{\text {st }}$ partial day and last partial days from the NWP results (the NWP output does not start at 00:00 local time).

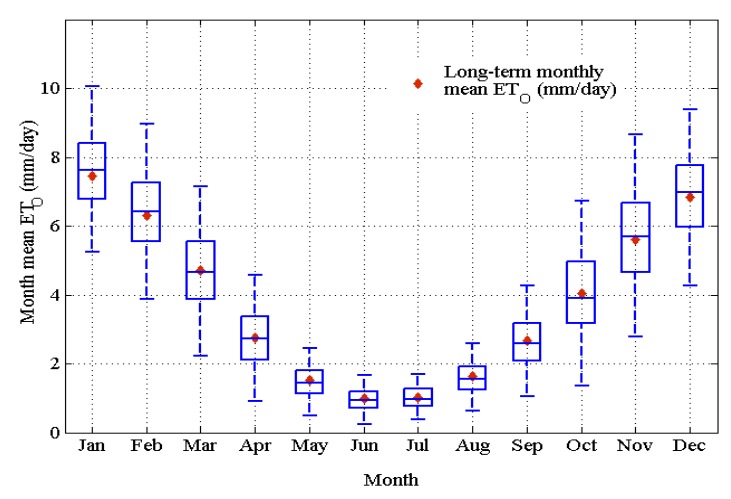

Figure 2. Seasonal variation of $E T_{O}$ in Shepparton irrigation area

\subsection{Forecasting ability of weather variables}

The statistical indices for the forecast performance for daily maximum and minimum air temperature $\left(T_{\max }\right.$ and $\mathrm{T}_{\min }$ ), daily maximum and minimum dew point temperature $\left(\mathrm{Dewpt}_{\max }\right.$ and $\left.\mathrm{Dewpt}_{\min }\right)$, daily mean wind speed and incoming shortwave solar radiation $\left(\mathrm{R}_{\mathrm{s}}\right)$ are shown in Figure 3. The forecast performance declines with increasing lead time. Uncertainties in observed weather variables were significantly lower than uncertainty of corresponding forecast variables for all lead time. $\mathrm{T}_{\max }$ and $\mathrm{T}_{\min }$ forecasts had $95 \%$ confidence intervals of \pm 2.99 and $\pm 3.34{ }^{\circ} \mathrm{C}$ (one day lead) against $\pm 0.3^{\circ} \mathrm{C}$ for the observation. Similarly, uncertainty for the satellite based "observed" $R_{s}$ values was $\pm 1.5 \mathrm{MJm}^{-2}$ during summer (Bureau of Meteorology, 2005) against the forecast uncertainty forecast of $\pm 9.55 \mathrm{MJm}^{-2}$ for $\mathrm{R}_{\mathrm{s}}$.

The RMSE values for the weather variables considered approximately doubles as the lead time increases from 1 to 9 days, with the exception of the daily mean wind speed. The RMSE values of $\mathrm{T}_{\max }$ were higher than those for $T_{\min }$ for the first two days, but it reversed later. The RMSE values of Dewpt $\mathrm{min}_{\min }$ were always more than Dewpt $t_{\max }$. Therefore, here the ACCESS-G forecast performance for maximum air and dew point temperatures is higher than for the corresponding minimums. In terms of daily mean wind speed and $\mathrm{R}_{\mathrm{s}}$, the RMSE values ranged between 3.84 and $4.42 \mathrm{kmh}^{-1}$ and between 3.16 and $6.32 \mathrm{MJm}^{-2} \mathrm{day}^{-1}$, respectively.

The $r^{2}$ between forecast and observed weather variables was more than 0.60 up to 7 days lead time, with the exception of Dewpt $t_{\min }$ and daily mean wind speed. $T_{\max }$ yielded the best $\mathrm{r}^{2}$ values for all lead times and even at 9 lead days it was 0.73 . The worst $r^{2}$ values were found for the daily mean wind speed which ranged between 0.02 and 0.33 , followed by the Dewpt min which ranged from 0.27 to 0.81 . The ACC measures correlation between the anomalies of the forecast and observed weather variables from the corresponding long-term monthly mean (climatology). If ACC is close to 1, it implies that there is a strong linear relationship between the temporal pattern of the forecast and observed anomalies. The best ACC values were found for $\mathrm{T}_{\text {max }}$ and the other variables were in the following descending order Dewpt $t_{\max }, \operatorname{Dewpt}_{\min }, \mathrm{R}_{\mathrm{s}}, \mathrm{T}_{\text {min }}$ and daily mean wind speed as shown in Figure 3(c).
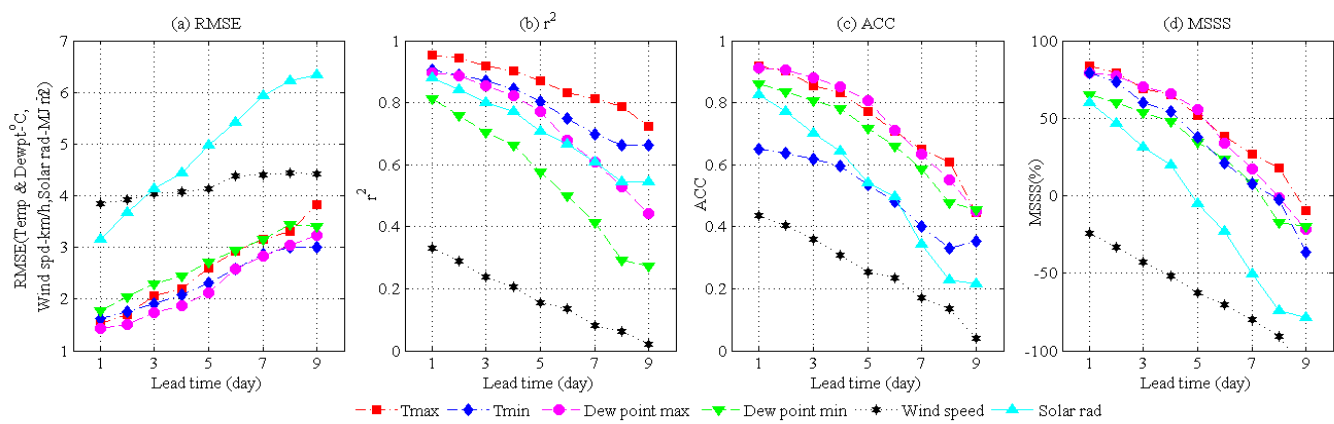

Figure 3. Forecast performance as indicated by (a) RMSE, (b) $r^{2}$, (c) ACC and (d) MSSS of forecasted vs. observed $\mathrm{T}_{\max }, \mathrm{T}_{\min }$, Dewpt $\mathrm{m}_{\max }$, Dewpt $\mathrm{min}_{\min }$, daily mean wind speed and $\mathrm{R}_{\mathrm{s}}$ at Shepparton airport.

The MSSS is based on anomalies from the monthly mean and measures ACCESS-G ability to forecast the short-term variations in weather variables. A value of $1(100 \%)$ indicates a perfect forecast and a value less than zero indicates that monthly climatology is a better predictor than the NWP. The MSSS values for 
Kushan Perera et al., Forecasting Daily Reference Evapotranspiration for Shepparton using Numerical Weather Prediction outputs

different weather variables were calculated and highest MSSS values were obtained for $\mathrm{T}_{\max }$. Other weather variables were in the following descending order Dewpt $t_{\max }, T_{\min }$, Dewpt $_{\min }, \mathrm{R}_{\mathrm{s}}$ and daily mean wind speed throughout the lead time as shown in Figure 3(d). For the one day lead time, the MSSS for all the weather variables considered was more than $60 \%$, with the exception of daily mean wind speed. It then gradually declines and falls below zero for lead times between 5 and 9 days, with the exception of daily mean wind speed. However, MSSS for daily mean wind speed was below zero for all lead times. Notably, for lead times up to 3 days, four out of six forecast variables were $50 \%$ better than the reference forecasts. These results indicate that ACCESS-G provides good forecasts of $E T_{O}$ related weather variables up to 3 lead days and that it is better than monthly climatology for lead times of up to a week.

\subsection{Forecasting performance for $E T_{O}$}

The FAO56-PM daily equation and the NWP forecasts were used to forecast $E T_{O}$ up to 9 days lead time. Daily forecasted $E T_{O}$ was then compared against "observed" $E T_{O}$ calculated using the observed hourly weather data at the Shepparton airport AWS and a satellite based measurement of global radiation. Figure 4 shows scatter plots of the $1,3,5$ and 7 day lead time forecasts vs. observed daily $E T_{O}$ values for the 0000 UTC ACCESS-G run. The increase in scatter between forecast and observed daily $E T_{O}$ values with the lead time was as a result of the weakened forecasting performance of the weather variables as discussed previously. To quantify the forecast performance for daily $E T_{O}$ the statistical performance indices were calculate (Table 1) and are plotted in Figure 5. As for the weather variables, forecast performance for $E T_{O}$ gradually declines with increased lead. The regression lines in Figure 4 shown that for small daily $E T_{O}$, the forecast very slightly over-predicted $E T_{O}$ whereas at the relatively

Table 1. Statistical indices of forecasted vs. observed $E T_{O}$ at Shepparton airport

\begin{tabular}{ccccc}
\hline $\begin{array}{c}\text { Lead } \\
\text { time } \\
\text { (days) }\end{array}$ & $\begin{array}{c}\text { RMSE } \\
\left(\mathrm{mm}^{-1}\right)\end{array}$ & $\mathrm{r}^{2}$ & ACC & $\begin{array}{c}\text { MSSS } \\
(\%)\end{array}$ \\
\hline 1 & 0.65 & 0.91 & 0.79 & 63.87 \\
2 & 0.72 & 0.89 & 0.77 & 56.17 \\
3 & 0.82 & 0.86 & 0.70 & 43.74 \\
4 & 0.85 & 0.85 & 0.67 & 39.63 \\
5 & 0.97 & 0.80 & 0.59 & 20.42 \\
6 & 1.01 & 0.79 & 0.57 & 14.12 \\
7 & 1.14 & 0.75 & 0.45 & -04.43 \\
8 & 1.17 & 0.73 & 0.40 & -12.25 \\
9 & 1.26 & 0.69 & 0.31 & -30.4 \\
\hline
\end{tabular}
high daily $E T_{O}$ values forecast under-predicted $E T_{O}$. This trend tended increase with lead time. On average, the forecast under-predicted $E T_{O}$ by $2 \%$ to $0 \%$ for lead times between 1 and 6 days and then over-predicted $E T_{O}$ by $0 \%$ to $4 \%$, for lead times between 7 and 9 days. These biases are small from a practical perspective.
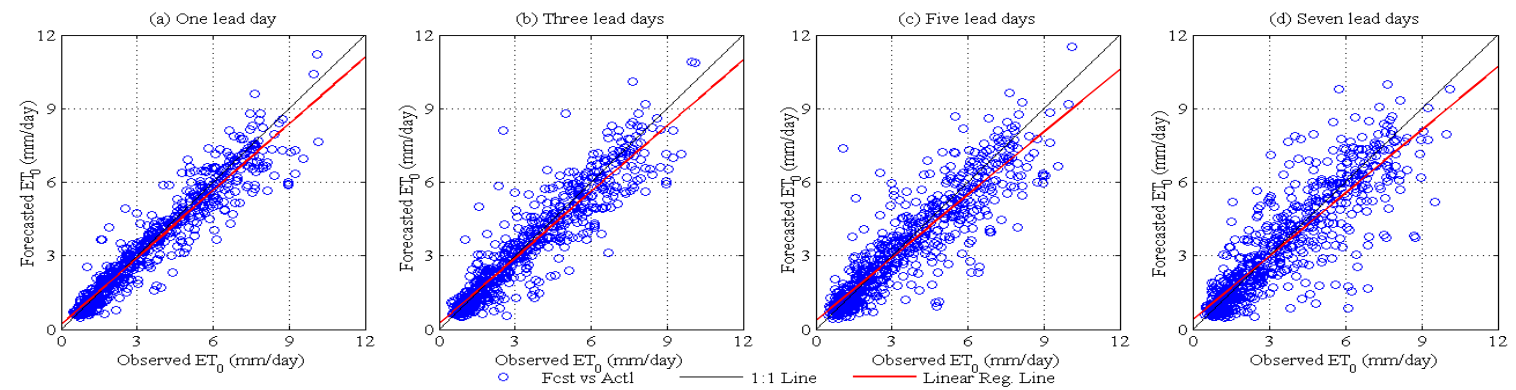

Figure 4. Daily $E T_{O}$ forecasted (NWP forecasts driven from ACCESS-G) vs. observed at the Shepparton airport: (a) One lead day, (b) Three lead days,(c) Five lead days and (d) Seven lead days
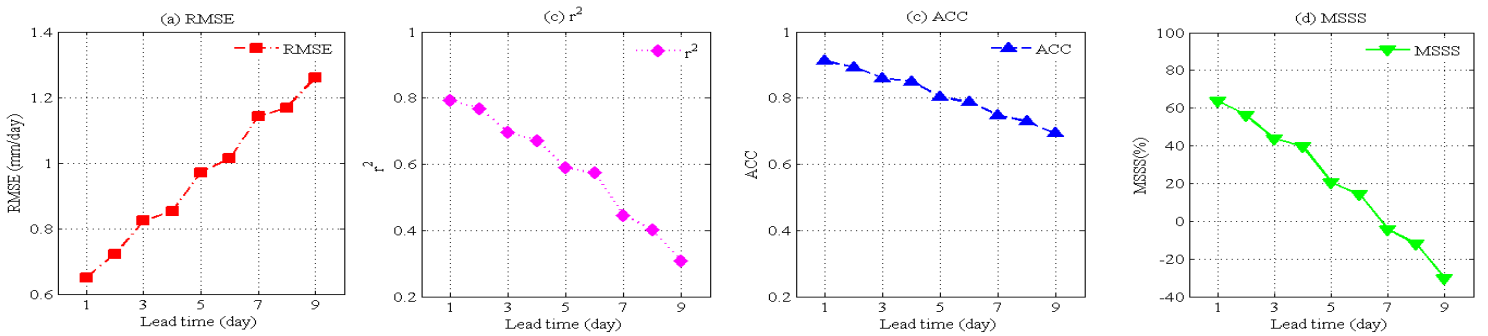

Figure 5. Statistical indices, (a) RMSE, (b) $\mathrm{r}^{2}$, (c) ACC and (d) MSSS of forecasted and estimated daily $E T_{O}$ at Shepparton airport

On average, the RMSE approximately doubled from 0.65 to $1.26 \mathrm{~mm} \mathrm{day}^{-1}$, as the lead time increased from 1 to 9 days. The correlation between forecast and observed $E T_{O}$ was very good for all lead times, with $\mathrm{r}^{2}$ values ranging from 0.91 ( 1 day lead time) to 0.69 (9 day lead time). This in part reflects the strong seasonality in $E T_{O}$. The ACC values ranged from 0.79 to 0.31 for 1 day to 9 day lead times. The MSSS progressively 
declined from 1 to 9 lead days, ranging from 64\% to $-30 \%$. The MSSS becomes negative after a lead time of 6 days. Therefore, for up to a lead time of 6 days, daily $E T_{O}$ forecasts made using NWP weather variable forecasts was better than using the long-term monthly mean $E T_{O}$. The declining performance of the $E T_{O}$ forecast is directly due to the declining forecast performance for the weather variables such as wind speed and solar radiation (George et al., 1985, Duce et al., 1999). Therefore, in the next section, we evaluate which forecast weather variable has the highest impact on the forecasting error of daily $E T_{O}$.

\subsection{Impact of weather variables forecasts to daily $E T_{o}$ forecasts}

In this section, four daily $E T_{O}$ forecasts were made by replacing one forecast weather variable (air temperature, dew point temperature, incoming solar radiation, daily mean wind speed) with the equivalent observation. The statistical indices computed using these forecasts are shown in Figure 6. All four performance indices show some improvement when the observations are used; however the differences for wind speed are marginal. The important point here for interpretation is that the larger the improvement (or sensitivity) gained by using corresponding observed weather variable the more important forecast errors in that variable are in terms of forecast errors in $E T_{O}$.
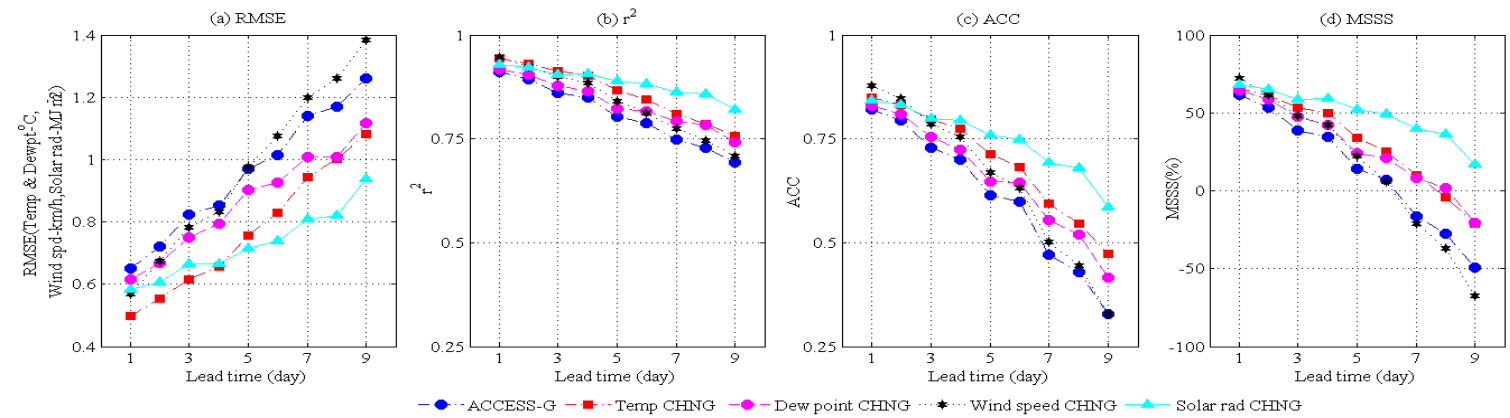

Figure 6. Statistical indices, (a) RMSE, (b) $\mathrm{r}^{2}$, (c) ACC and (d) MSSS of estimated and forecasted daily $E T_{O}$ by swapping observed variable one at a time at Shepparton airport

The largest improvements in RMSE were obtained by substituting observed air temperature during the first 4 lead days and by substituting observed global radiation after that. The patterns of improvement in $\mathrm{r}^{2}$ and ACC were very similar to each other. During a lead time up to 2 days, the greatest improvement in $r^{2}$ and ACC values were obtained by substituting observed daily mean wind speed. After a lead time of 2 days, using observed $R_{s}$ provided greatest improvement. In terms of MSSS, for one lead day, wind speed lead to the greatest improvement, followed by $R_{s}$. For longer lead times, using observed $R_{s}$ provided the best improvement followed by observed air temperature, daily mean wind speed and then dew point temperature. The impact of weather variables forecasts on the daily $E T_{O}$ forecast vary with the lead time, with greater improvements at longer lead times. The result suggests that improvements in incoming solar radiation forecasts would lead to the greatest gains in $E T_{O}$ forecasts.

\section{CONCLUSION}

Short-term $E T_{O}$ forecasts would be useful in making short-term real-time irrigation decisions. There is an opportunity to forecast daily $E T_{O}$ from the mesoscale NWP systems like ACCESS-G. This paper quantifies the forecast performance for $E T_{O}$ using weather variables from the Bureau of Meteorology's operational NWP forecasts derived from ACCESS-G for the Shepparton irrigation area.

Daily $E T_{O}$ was forecast for lead times up to 9 days and evaluated against "observed" $E T_{O}$ calculated using observed weather data from the Shepparton automatic weather station. The results showed that ACEESS-G is capable of generating skilful weather variables forecasts up to 3 days ahead and that for lead times up to 7 days ACCESS-G's NWP forecasts are better than the monthly mean climatology. Moreover, daily $E T_{O}$ forecasts calculated using NWP weather variable forecasts were better than the long-term monthly mean $E T_{O}$ for lead times up to 6 days, after which the long-term monthly mean $E T_{O}$ provided a better forecast. Furthermore, it was found that the largest source of error between forecast and observed $E T_{O}$ was the forecasting performance of incoming solar radiation, except for a lead time of one day where wind speed was slightly more important. This agrees with the forecast performance of the input weather variables where radiation and wind speed actually showed the lowest skill. In practice, farmers and irrigation system operators can rely on daily $E T_{O}$ forecasts computed using NWP forecasts derived from ACCESS-G for lead times of up to 6 days. 
Kushan Perera et al., Forecasting Daily Reference Evapotranspiration for Shepparton using Numerical Weather Prediction outputs

\section{ACKNOWLEDGEMENT}

The authors wish to express their gratitude to Dr Alan Seed and Dr Shaun Cooper, the Bureau of Meteorology, Australia for providing NWP forecasts derived from ACCESS-G for research purposes.

\section{REFERENCES}

Allen, R. G., Pereira, L. S., Raes, D. \& Smith, M. (1998). Crop Evapotranspiration - Guidelines for Computing Crop Water Requirements. Irrigation and Drain, Paper No. 56 , FAO, p. 300.

Arca, B., Duce, P., Snyder, R. L., Spano, D. \& Fiori, M. (2003). Use of numerical weather forecast and time series models for predicting ET . IV Int. Symp. on Irrigation of Horticultural Crops, 664, 2003. 39-46.

Bureau of Meteorology, Australia. (2010). Operational implementation of the ACCESS Numerical Weather Prediction systems. NMOC Operations Bulletin, 83.

Bureau of Meteorology, Australia. (2005). AWS's for Agricultural and Other Applications.

Cai, J., Liu, Y., Lei, T. \& Pereira, L. S. (2007). Estimating $E T_{O}$ with the FAO Penman-Monteith equation using daily weather forecast messages. Agricultural and Forest Meteorology, 145, 22-35.

Duce, P., Snyder, R. \& Spano, D. (1999). Forecasting reference evapotranspiration. III International Symposium on Irrigation of Horticultural Crops, 537, 1999. 135-141.

George, W., Pruitt, W. O. \& Dong, A. (1985). Evapotranspiration modelling, in CIMIS Final Report 10013A. Land, Air, and Water Research Paper Series, B53812, pp. 3.36-3.61.

Hargreaves, G.H., and Z.A. Samani. (1985). Reference crop evapotranspiration from temperature. Applied Engineering in Agriculture. 1:96-99.

Jensen, M. 1968. Water Consumption by Agricultural Plants. Water Deficits and Plant Growth. Plant water consumption and response, $2,1$.

Kumar, M., Raghuwanshi, N. S., Singh, R., Wallender, W. W. \& Pruitt, W. O. (2002). Estimating Evapotranspiration using Artificial Neural Network. J. Irrigation \& Drainage Engineering, 128, 224.

Marino, M. A., Tracy, J. C. \& Taghavi, S. A. (1993). Forecasting of reference crop evapotranspiration. Agricultural Water Management, 24, 163-187.

Miyakoda, K., Hembree, G., Strickler, R. \& Shulman, I. (1972). Cumulative results of extended forecast experiments I. Model performance for winter cases. Monthly Weather Review, 100, 836-855.

Mohan, S. \& Arumugam, N. (1995). Forecasting weekly reference crop evapotranspiration series. Hydrological Sciences Journal, 40, 689-702.

Murphy, A. H. 1988. Skill scores based on the mean square error and their relationships to the correlation coefficient. Monthly Weather Review, 116, 2417-2424.

Peel, M. C., Finlayson, B. L. \& Mcmahon, T. A. (2007). Updated world map of the Köppen-Geiger climate classification. Hydrology \& Earth System Sciences, 11, 1633-1644.

Penman, H.L., (1948). Natural evaporation from open water, bare soil and grass. Proceedings of the Royal Society of London. Series A: Mathematical and Physical Sciences 193: 120-146.

Raghuwanshi, N. S. \& Wallender, W. W. (1999). Forecasting and optimizing furrow irrigation management decision variables. Irrigation Science, 19, 1-6.

Silva, D., Meza, F. J. \& Varas, E. (2010). Estimating reference evapotranspiration using numerical weather forecast data in central Chile. Journal of Hydrology, 382, 64-71.

Tahir, S. A. 1998. Estimating potential evaporation using artificial neural network. Water land resources, 2.

Tian, D. \& Martinez, C. J. (2012). Forecasting Reference Evapotranspiration Using Retrospective Forecast Analogs in the South-eastern United States. Journal of Hydrometeorology, 13, 1874-1892.

Trajkovic, S., Todorovic, B. \& Stankovic, M. (2003). Forecasting of Reference Evapotranspiration by Artificial Neural Networks. Journal of irrigation and drainage engineering, 129, 454-457.

Xianghong, G., Xihuan, S. \& Juanjuan, M. (2011). Prediction of daily crop reference evapotranspiration values through a least-squares support vector machine model. Hydrology Research, 42(4), 268-274. 